\title{
Role of HIV-1 Infection in Addictive Behavior: A Study of a HIV-1 Transgenic Rat Model
}

\author{
${ }^{1}$ Sulie L. Chang and ${ }^{2}$ Michael Vigorito \\ ${ }^{1}$ Department of Biology, ${ }^{2}$ Department of Psychology, Seton Hall University, South Orange, NJ 07079
}

\begin{abstract}
Epidemiological research indicates that drug abuse is prevalent among individuals infected with HIV-1. Evidence from preclinical research also suggests that drugs of abuse exacerbate the progression of neuropathological changes in the HIV-1 infected brain probably through common mechanisms of neuronal injury. The effects of HIV-1 on the efficacy and abuse potential of controlled drugs such as morphine, however, has not been explored. The current study reports that the noninfectious HIV-1 transgenic (HIV-1 Tg) rat shows up-regulated expression of the mu opioid receptor (MOR) at the transcriptional level and functional supersensitivity to morphine, a MOR agonist. Compared to nontransgenic control rats, the HIV-1 Tg rats also show greater motivation to run in a wheel, a behavior that is known to be associated with increased drug self-administration. These results suggest the potential role of HIV-1 infection in enhancing vulnerability to addiction and this possibility warrants further investigation to better understand the link between HIV-1 infection and the abuse of drugs including opioids.
\end{abstract}

Key words: HIV, morphine, mu opioid receptor, wheel running, addiction

\section{INTRODUCTION}

Epidemiologic research on the human immunodeficiency virus (HIV) epidemic has consistently indicated a strong correlation between the use of abused drugs and HIV infection ${ }^{[1]}$. One reason for this relationship is that drug abuse is a significant mode of HIV transmission, either through injection of drugs using blood-contaminated needles or through increased high risk behavior (e.g., unprotected sex under the influence of drugs or in exchange for drugs $)^{[2]}$. The connection between drug abuse and HIV is much more complex than this, however. Drugs of abuse and HIV-1 have been shown to act on similar neurobiological substrates. Numerous studies have shown that drugs of abuse can enhance the replication of HIV and progression of neurological complications in AIDS. Another possibility that has received less attention is that HIV infection may affect the host's use or abuse of addictive drugs.

Drug abuse is higher among persons with risk for HIV infection, but especially among those who are HIV seropositive. In one study on urban gay men, for example, multiple and frequent drug use was more likely to be reported by HIV-positive $\operatorname{men}^{[3]}$. HIV infection is also positively correlated with increased drug use among high risk youths ${ }^{[4]}$. Among injection drug users recruited for substance abuse treatment, HIV infected persons ceased injecting drugs sooner than non-infected users, but were also quicker to subsequent relaps $^{[5]}$. In the United States, about $25 \%$ of the general public smoke cigarettes, but smoking rates in the HIV seropositive population is 2 to 3 times more prevalent $^{[6,7]}$. In one study on New England HIV patients, greater than $75 \%$ smoked and over $80 \%$ of the smokers were not considering quitting ${ }^{[6]}$. The latter observation, which suggests a lack of motivation to quit or greater difficulty in quitting, has also been observed in a more recent study ${ }^{[8]}$. Moreover, HIV seropositive individuals who are smokers are also more likely to develop AIDS dementia complex (ADC) ${ }^{[9]}$.

Antiretroviral therapies (ARV) such as Highly Active Antiretroviral Therapy (HAART) were introduced in 1996. The therapy consists of inhibitors that target viral entry, reverse transcriptase and viral protease to control viral replication, restore immunity and delay disease progression. However, it cannot eliminate infection ${ }^{[10-14]}$. Although the incidence of AIDS and mortality has declined and AIDS is no longer a rapidly fatal disease, the current clinical challenge is that HIV infection is now a chronic disease and the hosts are in the course of continuous infection ${ }^{[14-16]}$. The prolongation of life and continuity of HIV infection have resulted in a corresponding increase in health problems including age-related conditions and HIVrelated neurological and neuropsychological complications. Furthermore, the impact of HIV-1 infection on the nervous system appears to be exacerbated by drugs of abuse. It has been reported that persistent drug users and patients who switched to drug use during the course of an ARV regimen are more likely to show non adherence with treatment protocols ${ }^{[17,18]}$. Drug abuser's reduced adherence to HIV treatment regimens seems to suggest that there are complex interactions between HIV infection and the use of addictive drugs as they act on the same neurobiological systems. 
HIV-1 has its devastating effects by targeting the cells of the immune system. It is well documented that drugs of abuse such as heroin and opioids affect the immune system directly ${ }^{[19]}$ in addition to their indirect $^{[20]}$ effects through interactions with neural pathways ${ }^{[21]}$. HIV-1 gp120 has also been observed to regulate expression of mu opioid receptor (MOR) at the mRNA and protein levels of the immune cells ${ }^{[22]}$.

Drugs of abuse, including psychomotor stimulants, opioids and nicotine, have their rewarding effects by acting on the mesocorticolimbic dopaminergic system. HIV-1 infection appears to affect these neural structures too. HIV-1 does not infect neurons directly, but by targeting macrophages, microglia and to a lesser extent, astrocytes $^{[23,24]}$. The mechanisms that result in neural damage and cell loss is not well understood, but they appear to involve the shedding of soluble viral proteins and neurotoxins such as gp120 and TAT, as well as the elevation of proinflamatory cytokines, excitatory amino acids (e.g., glutamate) and chemokines ${ }^{[25,26]}$. In the latest stages of HIV-1 infection in some individuals neural pathology results in severe motor deficits that are characteristic of Parkinson's disease ${ }^{[27]}$. When motor symptoms are accompanied with motivational and cognitive deficits (in about 20\% - 30\% of HIV-1 infected people ${ }^{[24]}$, HIV dementia or ADC is indicated. More subtle neuropsychological deficits described as minor cognitive/motor disorder (MCMD) have also been observed in patients with advanced infection ${ }^{[28]}$. Moreover, although the introduction of HAART has decreased the incidence of ADC (primarily by reducing the opportunistic infections caused by immunosuppression) the cumulative prevalence of ADC continues to increase and the incidence of MCMD appears unchanged ${ }^{[29]}$. The neurological deficits seen in ADC and MCMD parallel the symptoms of subcortical dementia thereby implicating the mesocorticolimbic dopamine system ${ }^{[30]}$. Interestingly, it is this neural system that is implicated in the rewarding and behavioral activation of abused drugs. Although dopamine is most often associated with this pathway in the literature, considerable evidence indicates that other neurotransmitters play a role. For example, dopamine and opioids are colocalized in the striatum and work together to modulate the rewarding effects of abused $\operatorname{drugs}^{[31]}$.

The drug abuse/HIV literature has emphasized how drugs of abuse impact on the progression of HIV infection and disease. However, given the common neural substrates in which HIV and drugs of abuse act, it is plausible that HIV infection affects the psychological impact of drugs and possibly even the vulnerability to drug abuse. Extant theories of drug addiction emphasize the role of the positive reinforcing or hedonic properties of drugs in escalating behavior from drug use to drug abuse and addiction ${ }^{[32,33]}$. These theories suggest that the progressive increase in a drug's addictive properties reflects a sensitization process. Behavioral sensitization occurs when repeated administration of psychostimulants or morphine increases the psychomotor stimulating and rewarding effects of the drug. Several studies indicate that opioids mediate the sensitization effects of several drugs. Repeated amphetamine administration causes behavioral sensitization and upregulation of mu opioid receptor mRNA in the dorsal striatum ${ }^{[34]}$. Cocaine administration also upregulates mu-opioid receptors in the dopamine-rich areas of the striatum ${ }^{[31]}$. Any neurobiological change that facilitates sensitization may increase vulnerability to addiction. As mentioned previously HIV-1 regulates mu-opioid receptors in immune cells. Thus, one way that the HIV-1 virus may hasten sensitization and increase addictive behavior is through the upregulation of neuronal mu-opioid receptors. Another mechanism may be through the activation of the HPA axis. There is considerable preclinical and some clinical evidence that stress increases the positive reinforcing properties of some drugs of abuse (i.e., psychomotor stimulants) through the acute activation of the hypothalamic-pituitaryadrenal (HPA) axis ${ }^{[35]}$. Stress-induced changes in the HPA axis, therefore, may synergize with drug effects to enhance sensitization ${ }^{[36]}$.

But within the framework of current theories of addiction, the total breakdown of self-regulated behavior that occurs in the final stages of drug addiction most likely reflects a profound dysregulation of neurobiological systems ${ }^{[32]}$. Thus, although a hyperactive HPA axis is correlated with the enhanced rewarding properties of acute administration of drugs of abuse, a hypoactive HPA axis is associated with abnormally persistent drug use ${ }^{[37]}$. Addiction may reflect behavioral attempts to increase the activity in these dysregulated neurobiological systems ${ }^{[32]}$. Any genetic predisposition that accelerates the path toward dysregulated motivational/neurobiological systems presumably will increase vulnerability to drug addiction. There is compelling evidence, for example, that individual differences in responding to non-drug reinforcers are predictive of drug abuse. Rats that are more responsive to palatable tastes ${ }^{[38]}$ or novel objects in a novelty-seeking task ${ }^{[39]}$ are more likely to selfadminister drugs. A propensity towards wheel running in rodents is also associated with an increased vulnerability for drug self-administration ${ }^{[40]}$. Wheel running as a motivated, self-reinforcing, behavior is an especially intriguing behavior because it can escalate to resemble an addiction in and of itself and when the opportunity to run is made available to food deprived rats, self-regulated behavior can breakdown, resulting in excessive running and profound anorexia ${ }^{[41]}$. These and other behavioral predispositions (impulsivity) may make individuals more vulnerable to drug abuse by hastening the progression toward homeostatic dysregulation $^{[32]}$. The development of brain pathology may also result in similar dispositions that increase 
vulnerability toward pathological drug use. The dysregulation of the mesolimbic dopamine system in schizophrenia $^{[42]}$ and depression ${ }^{[43]}$ may contribute to the increased drug use seen in individuals with these diagnoses. We acknowledge that the persistent infection of the brain by HIV-1 may also result in neurological dysfunction that compromises the individual's ability to regulate drug use.

Evidence for the impact of HIV infection on vulnerability to drug abuse is very difficult to determine from epidemiological and clinical studies because of the numerous confounding variables. Animal models of HIV are needed to evaluate the effect of HIV-1 on factors ranging from the behavioral to the molecular level that may increase vulnerability to addiction. Although there are several animal models for understanding HIV infection and AIDS, we suggest that the recently developed noninfectious HIV-1 transgenic rat $^{[2]}$ may be an important animal model for further study because it may more closely model HIV-1 infection in the post-HAART era in which HIV is treated as a manageable, chronic disease by suppressing viral replication.

HIV-1 infection results from the actions of viral proteins, including the envelope glycoprotein 120 (gp120), on targeted cells, such as macrophages and Tlymphocytes $^{[44-49]}$. HAART suppresses the growth of HIV-1 but does not eliminate HIV-1 infection ${ }^{[10-14]}$. The clinical challenge in this post-HAART era is, therefore, the persistent infection that results from the presence of HIV viral proteins in the host ${ }^{[14,17,16,50]}$. The HIV Tg rat model carries a gag-pol-deleted HIV-1 genome under the control of the HIV-1 viral promoter and expresses 7 of the $9 \mathrm{HIV}$ genes ${ }^{[51]}$. Thus, while there is no viral replication in the HIV $\mathrm{Tg}$ rat model, viral proteins are expressed in various organs and in the circulating blood of this animal model ${ }^{[51]}$.

In the present study, we used the HIV-1 Tg rat as an experimental animal model to explore how persistent HIV infection may affect molecular and behavioral variables that are associated with vulnerability to addictive behaviors. To evaluate the effects of HIV-1 infection at the molecular level, we concentrated on the mu opioid receptor (MOR) because it is known to play a role in the analgesic and the rewarding effects of morphine and modulates the drug-induced changes in the dopaminergic mesocorticolimbic system. We evaluated the rostral brain which is rich in MOR mRNA and includes nigrostriatal and mesolimbic dopamine systems that are the main targets of addictive $\operatorname{drugs}^{[52]}$ and the hypothalamus because of the link between stress and addiction and the role of the opioids in regulating the HPA axis. At the behavioral level we examined wheel running behavior. In a previous unpublished study we observed an increased propensity for running and significantly lower blood corticosterone levels in the HIV1-Tg rats compared to controls. Because high motivation to run is correlated with an increased vulnerability to drug self-administration in rodents this observation intrigued us. However, the HIV-1 Tg rats were lighter in body weight than the controls which may have accounted for the observed differences in running. In the present study we tested groups that were closer in body weight.

\section{MATERIALS AND METHODS}

Morphine sulfate was obtained from SigmaAldrich (St. Louis, MO). TRIzol reagent for RNA extraction was obtained from Invitrogen (Carlsbad, CA). Oligonucleotides for real-time RT-PCR were synthesized and purified by Integrated DNA Technologies, Inc. (Coralville, IA).

Animals: Male HIV-1 transgenic (Tg) rats and F344/NHsd control background strain rats were purchased from Harlan, Inc. (Indianapolis, IN). The animals were singly housed in standard plastic rodent cages or in flexible-film isolators in a temperaturecontrolled environment with standard rat diet and water available ad libitum. All experimental procedures were conducted during the light period of a 12-h light/dark cycle and were approved by the Institutional Animal Care and Use Committee of Seton Hall University.

Behavioral measures: Five HIV-1 $\mathrm{Tg}$ rats and five F344 control rats matched for body weight were tested in Wahman-type running wheels (1.2 M circumference) for their motivation to run when they were approximately $6 \mathrm{mo}$. of age. Tests were conducted in the afternoon for $30 \mathrm{~min}$. beginning at approximately 1:00 pm. The number of rotations per session was recorded. All rats were tested for $12 \mathrm{~d}$. When these same rats were approximately $11 \mathrm{mo}$. of age they were assessed for morphine's antinociceptive properties using a tail flick analysis meter (II TC Life Science, Mod 33). The radiant heat source was calibrated to produce baseline latencies of 3-4 $\mathrm{s}$ and a maximum latency of 8-9 s was set to prevent tissue damage to the tail. Three trials were conducted for each rat with an inter-trial interval of $1 \mathrm{~min}$. The latencies to change the tail position in response to the heat source were averaged to yield a mean latency score.

Cumulative morphine dose-response experiment: Cumulative dose-response curves ${ }^{[53]}$ were calculated to evaluate the antinociceptive effect of morphine on tailflick latencies. After the initial baseline tail flick measurement the rats were given $0.3 \mathrm{mg} / \mathrm{kg}$ of morphine (s. c.) and tail-flick latencies were measured again after $30 \mathrm{~min}$. The subsequent dose of morphine was increased by $0.3 \log$ unit (i.e. $0.56,1,1.75,3,5.6$ and $10 \mathrm{mg} / \mathrm{kg}$ ) of morphine, with tail-flick measurement always occurring $30 \mathrm{~min}$. after each injection. This procedure was continued until either the rat failed to flick the tail within the cut-off time or there 
was no further increase in tail-flick latencies from one dose to the next. The cumulative dose-response curves of the tail-flick latency as a function of the morphine dosage were generated. ED-50 scores, defined as the morphine dosage which results in $50 \%$ of the maximal possible antinociceptive effects ${ }^{[53]}$ were also calculated.

Total RNA isolation: Two additional HIV-1 Tg rats and two F344 rats, all approximately 12 mo. of age, were sacrificed. The hypothalamus from each of the HIV-1 Tg rats was dissected out and the two were pooled together; likewise, the hypothalamus from each of the F344 rats was removed and pooled together. Half of the rostral brain from each of the HIV-1 Tg rats was dissected out and the two were pooled together; half of the rostral brain from each of the F344 rats was removed and pooled together. Total RNA from the each pooled specimen was isolated using TRIzol $^{\mathrm{TM}}$ reagents according to the manufacturer's protocol (Invitrogen, GIBCO BRL Life Tech., Grand Island, NY). Total RNA was suspended in $30 \mu \mathrm{l}$ of DEPC $\mathrm{H}_{2} \mathrm{O}$ and the concentration of the RNA was spectrophotometrically determined at $260 \mathrm{~nm}$. The integrity of the RNA in each of the samples was assessed on a $0.8 \%$ agarose gel containing ethidium bromide $(\mathrm{EtBr})$ and the bands were visualized by UV transillumination. The prepared total RNA solution was kept at $-80^{\circ} \mathrm{C}$. Three aliquots of 1 $\mu \mathrm{g}$ RNA each, from the rostral brain and hypothalamus samples, from the HIV-1 Tg and F344 rats were used to prepare cDNA using reverse transcriptase.

Real-time reverse transcriptase-polymerase chain reaction (RT-PCR): An aliquots of $2 \mu 1$ of the cDNA samples prepared as above was amplified by real-time RT-PCR in $50 \mu 1$ of PCR master mix ( $25 \mu 1$ of $1 X$ PCR Mastermix, $400 \mathrm{nM}$ of each primer, TaqMan probe, in $24.7 \mu \mathrm{l}$ of DEPC $\mathrm{H}_{2} \mathrm{O}$ ) using an ABI Prism 7000 (Applied Biosystems, Foster City, CA) as previously reported (Beltran, 2006a, Beltran, 2006b). The PCR primers for amplification and the TaqMan probes used for rat MOR and GAPDH are listed in Table 1. Both the MOR and GADPH probes were labeled with a fluorophore, 6-carboxyfluorescein (FAM), at the 5' end and a quencher, 4-(4'-dimethylaminophenylaso) benzoic acid (DABCYL), at the 3' end. Thermal cycling conditions include an initial denaturation step for $10 \mathrm{~min}$ at $95^{\circ} \mathrm{C}$, then 45 cycles for $18 \mathrm{~s}$ at $95^{\circ} \mathrm{C}$, followed by $1 \mathrm{~min}$ at $60^{\circ} \mathrm{C}$. At the end of each PCR run, the data were automatically analyzed by the system and amplification plots were obtained. A MOR RNA standard curve was generated to quantify the MOR mRNA; known amounts of the MOR RNA standard was serially diluted 10 -fold and amplified in the same plate under the same conditions. The quantity of MOR mRNA in the samples was calculated from the standard curve. For normalization of MOR mRNA levels, a GADPH mRNA fragment in these samples was also amplified and used to calculate the MOR mRNA copy number per microgram of total RNA. All amplification reactions were performed in triplicate.

Statistical analysis: Mean wheel rotations and tail flick latencies were analyzed with separate two-way ANOVAs using SPSS software. Groups (HIV-1 Tg vs. F344) was the between subjects factor for both dependent variables and days (12) and dosage (6) was the within subjects factor for wheel rotations and tail flick latencies, respectively. MOR mRNA signals were analyzed using independent t-tests. Statistical significance was accepted at $\mathrm{p}<0.05$.

\section{RESULTS}

Running wheel behavior in HIV Tg rats: The HIV-1 $\mathrm{Tg}$ and F344 rats were tested in running wheels during daily $30 \mathrm{~min}$. sessions when they were approximately 6 mo. of age. To evaluate the possibility that our previous observations were a result of lower body weights in the HIV-1 Tg animals we tried to more closely match body weights between groups. The mean body weight of the HIV-1 $\mathrm{Tg}$ rats $(\mathrm{M}=343 \pm 15.5 \mathrm{~g})$ was slightly greater than the $\mathrm{F} 344$ rats $(M=311.6 \pm 4.6)$. Figure 1 shows the mean rotations of the HIV-1 Tg rats compared to F344 controls in the running wheel during daily $30 \mathrm{~min}$. sessions. The gap between Days 5 and 6 and between Days 8 and 9 indicate suspensions in testing for 4 and 2 $\mathrm{d}$, respectively. There was a significant main effect of days $[\mathrm{F}(11,44)=2.87, \mathrm{p}<.01)$ and a group $\mathrm{x}$ days interaction $[\mathrm{F}(11,44)=4.01, \mathrm{p}<.001)$. There were no differences in running during the first $5 \mathrm{~d}$, but on all subsequent days the HIV-1 Tg rats ran significantly more than the F344 controls ( $\mathrm{ps}<.05)$.

Antinociceptive response of $\mathrm{HIV}-1 \mathrm{Tg}$ rats to morphine: The same animals used in the running wheel experiment were also tested for their antinociceptive response to morphine at approximately 12 mo. of age. The mean tail flick latencies (Figure 2) of morphine dose-response curve was shifted to the left for the HIV-1 Tg rats indicating an increased potency of morphine's antinociceptive properties (groups $\mathrm{x}$ dose interaction $[\mathrm{F}(5,20)=5.50, \mathrm{p}<.01])$. The Tail flick latencies were significantly higher in the HIV-1 Tg rats at the $0.56,1.0$ and $1.75 \mathrm{mg} / \mathrm{kg}$ dose $(\mathrm{ps}<.05)$. The ED50 value for the HIV-1 Tg rat was lower than that for the $\mathrm{F} 344$ animals $(0.20 \pm 0.042 \mathrm{mg} / \mathrm{kg}$ versus $0.42 \pm$ $0.091 \mathrm{mg} / \mathrm{kg})$.

Mu opioid receptor expression in HIV-1 Tg rat brain areas: To evaluate the expression of the mu opioid receptor (MOR) in the brain of the HIV-1 Tg rats, MOR mRNA levels from the hypothalamus and rostral brain, respectively, of 12-mo old HIV-1 Tg rats were compared with those from F344 control rats. 
American J. Infectious Dis., 2(2): 98-106, 2006

Table: 1: PCR Primers for Amplification and the TaqMan probes used for MOR and DAPDH

\begin{tabular}{|c|c|c|c|c|}
\hline mRNA & \multicolumn{2}{|r|}{ Oligonucleotide Nucleotide Sequence } & $\begin{array}{c}\text { PCR Product } \\
\text { size }(\mathrm{BP})\end{array}$ & Reference \\
\hline \multirow{3}{*}{$\begin{array}{l}\text { Human } \\
\text { MOR }\end{array}$} & Sense: & 5'-TCA-TCA-TTA-CCG-TGT-GCT-ATG-GA-3' & \multirow{3}{*}{79} & \multirow{3}{*}[54]{} \\
\hline & Anti-Sense: & 5'-TCC-TT-TCT-TTG-GAG-CCAGAGA-A-3' & & \\
\hline & Tag-Man Probe: & 5'-CTT-GCG-CCT-CAA-GAG-TGT-CCG-CA-3' & & \\
\hline Human & Sense: & 5'-GGA-AGC-TCA-CTG-GCA-TGG-C-3' & \multirow{3}{*}{97} & \multirow{3}{*}{ [54] } \\
\hline \multirow[t]{2}{*}{ GAPDH } & Anti-Sense: & 5'-CCC-CAC-TGC-CAA-CGT-GTC-AGT-G-3' & & \\
\hline & Tag-Man Probe: & 5'-CCC-CAC-TGC-CAA-CGT-GTC-AGT-G-3' & & \\
\hline Rat & Sense: & 5'-CAG-CCC-TTC-CAT-GGT-CAC-AG-3' & \multirow{3}{*}{257} & \multirow{3}{*}[55,56]{} \\
\hline \multirow[t]{2}{*}{ MOR } & Anti-Sense: & 5'-TAC-TGG-TCG-CTA-AGG-GGT-CTG-3' & & \\
\hline & Tag-Man Probe: & 5'-CAT-TTT-GGT-GTA-TCT-TAC-AAT-CAC-AT-3' & & \\
\hline Rat & Sense: & 5'-GAA-CAT-CAT-CCC-TGC-ATC-CA-3' & \multirow{3}{*}{78} & \multirow{3}{*}{$\begin{array}{c}\text { Unpublished } \\
\text { Data }\end{array}$} \\
\hline \multirow[t]{2}{*}{ GAPDH } & Anti-Sense: & 5'-CCA-GTG-AGC-TTC-CCG-TTC-A-3' & & \\
\hline & Tag-Man Probe: & 5'-CTT-GCC-CAC-AGC-CTT-GGC-AGC-3' & & \\
\hline
\end{tabular}

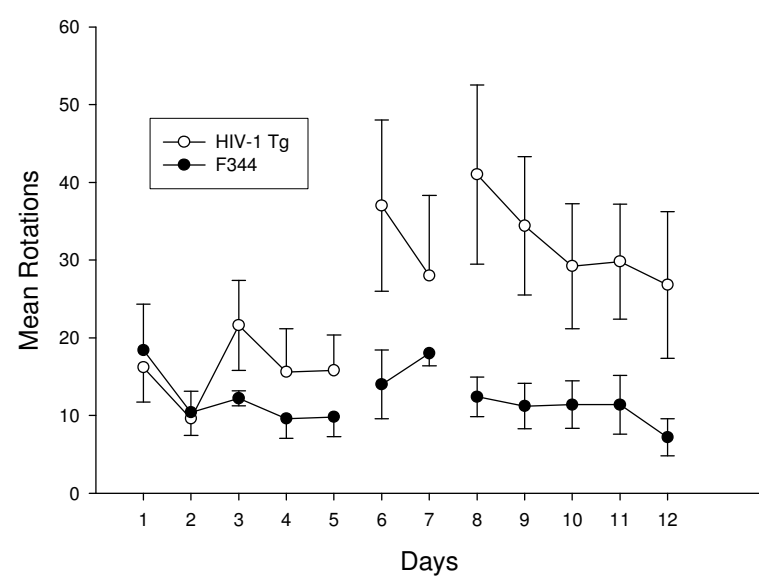

Fig. 1: Mean $( \pm$ SE) rotations in a running wheel during daily 30 min. access to running for 6 mo. of age HIV-1 Tg $(n=5)$ and F344 control rats $(n=5)$. Test days were done on consecutive days except at the points where there is a gap. There was a significant main effect of days $[\mathrm{F}(11,44)=2.87, \mathrm{p}<.01)$ and a group $\mathrm{x}$ days interaction $[\mathrm{F}(11,44)=4.01, \mathrm{p}<.001)$ as determined by a two-way ANOVA performed for all 12 days. There were no differences in running during the first $5 \mathrm{~d}$, but on all subsequent days the HIV-1 Tg rats ran significantly more than the F344 controls (ps<.05)

MOR mRNA was expressed at a significantly greater level in the rostral brain of HIV-1 Tg rats compared to that in the rostral brain of the control animals (Figures $3 \mathrm{~A}$ and $3 \mathrm{~B})[\mathrm{n}=3 ; \mathrm{t}(4)=10.12, \mathrm{p}<.05]$. This difference in MOR mRNA expression between the HIV-1 Tg rats and the F344 control rats was even more pronounced in the hypothalamus (Figures $3 \mathrm{C}$ and $3 \mathrm{D}) \quad[(\mathrm{n}=3 ; \mathrm{t}$ (4) $=24.99, \mathrm{p}<.001]$.

\section{DISCUSSION}

Clinical and preclinical studies indicate that drugs of abuse directly affect the progression of HIV infection and AIDS because HIV-1 and drugs of abuse act on the same neurobiological systems. It is therefore plausible to assume that there may be a reverse causal influence -

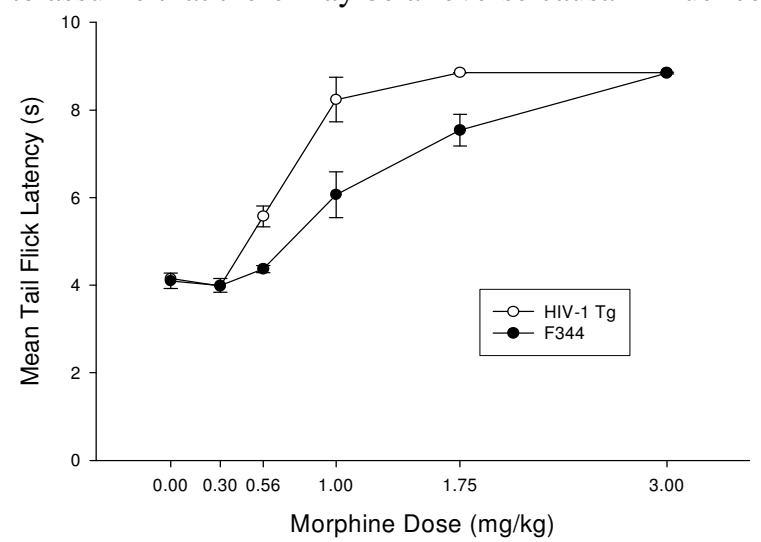

Fig. 2: Mean $( \pm \mathrm{SE})$ tail-flick latencies in 12 mo. of age HIV-1 Tg rats $(n=5)$ and F344 control rats $(n=5)$ as a function of cumulative increases in morphine dosage $(0.0 .3,0.56,1.0$, 1.75 and $3.0 \mathrm{mg} / \mathrm{kg}$ ). An increased potency of the morphine's antinociceptive properties in the HIV-1 Tg rats is indicated by a shifting to the left of the dose-response curve, $[\mathrm{F}(5,20)=5.50, \mathrm{p}<.01]$. The Tail flick latencies were significantly higher in the HIV-1 Tg rats at the 0.56, 1.0 and $1.75 \mathrm{mg} / \mathrm{kg}$ dose (ps<.05). The ED50 value for the HIV $-1 \mathrm{Tg}$ rat was lower than that for the F344 animals $(0.76 \pm 0.04 \mathrm{mg} /$ $\mathrm{kg}$ versus $1.15 \pm 0.08 \mathrm{mg} / \mathrm{kg}$ )

changes in the shared neural pathways as a result of HIV-1 infection may affect an individual's response to drugs of abuse and perhaps their vulnerability to addiction. The results of the present study suggest that HIV-1 infection may affect vulnerability to drug addiction at two different points in the path toward addiction.

The first point may be at the initial phase when the hedonic or reinforcing impact of acute drug administration controls behavior. HIV-induced changes that occur at the molecular or neural level of the mesocorticolimbic pathway, for example, may enhance 
the rewarding properties of drugs which, given the presence of other factors, may lead to drug abuse and addiction. That is, the factors that transition drug use into drug abuse and addiction may be shared among

\section{Rostral Brain}

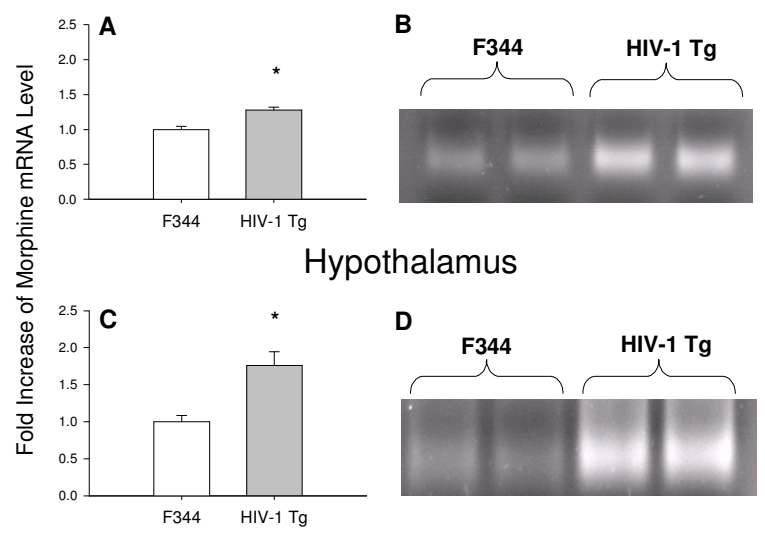

Fig. 3: Expression of MOR mRNA levels in the rostral brain and hypothalamus of HIV-1 Tg rats. Total RNA isolated from rostral brain and hypothalamus of 12 mo. old HIV-1 Tg and F344 control rats was examined for MOR expression using real-time RT-PCR. MOR mRNA in the rostral brain of HIV$1 \mathrm{Tg}$ rats was compared to that from F344 control rats (A). MOR mRNA in the hypothalamus of HIV-1 Tg rats was also compared to that from F344 control rats (C). The PCR products from the rostral brain and hypothalamus were electrophoresed on a $3 \%$ gel (B and D). $\mathrm{n}=3 ; * p<0.05$

HIV-infected and noninfected individuals, but the initial response to drug incentive stimuli may be exaggerated or sensitized as a result of infection. In the present study up-regulation of the MOR expression at the transcriptional level was observed in the rostral brain and hypothalamus of HIV-1 Tg rats, along with increased opioid agonist potency. Functional supersensitivity to opioid agonists is also seen following opioid antagonist-induced upregulation ${ }^{[54,55]}$ as predicted by drug receptor theory ${ }^{[56]}$. Studies with MOR knock out mice demonstrate that MOR mediates both the analgesic and rewarding or addictive properties of morphine ${ }^{[57]}$. Therefore, the increased MOR mRNA observed in the present study suggests that the HIV-1 $\mathrm{Tg}$ rats may be more sensitive to the rewarding properties of morphine.

Drug use and drug abuse does not necessarily lead to drug addiction, but when it does, it may be a "cycle of spiraling dysregulation" ${ }^{p 8]}$ that occurs at the behavioral and neurobiological levels that is responsible $^{[32,58]}$. Some genetic or neurological conditions may predispose individuals to a greater vulnerability toward this transition, such as a predisposed personality characteristic (sensation seeking) or a psychiatric diagnosis (schizophrenia, depression). Excessive behaviors maintained by nondrug reinforcers, such as gambling and compulsive running, may also indicate a predisposition towards homeostatic dysregulation. Thus, the second point at which HIV-1 may impact on addictive behavior is at the transition from controllable drug use (homeostasis) to uncontrollable drug use (homeostatic dysregulation). Neurobiological changes induced by HIV-1 such as a dysregulated HPA axis, altered neurotransmitter

systems and a change in motivational systems may facilitate the transition to a cycle of homeostatic dysregulation. In a previous unpublished study we observed an increased propensity for running in HIV1$\mathrm{Tg}$ rats that were lighter in body weight than nontransgenic control animals. In the present study we replicated our previous observation using groups that were closer in body weight, suggesting that the previous results were unrelated to the lower body weights of the HIV-1 Tg animals. Although considerable more work is needed to confirm a greater motivation to run in HIV-1 Tg animals, this result suggested to us that HIV-1 infection may cause a substantial change in motivation that may increase proneness to homeostatic dysregulation and therefore increased vulnerability to addiction.

The HIV-1 Tg rat may be a promising animal model to evaluate the relationship between changing neurobiological systems and a propensity towards addictive behavior. Because the transgenic model is noninfectious, it may also provide a useful model for evaluating neurobehavioral disturbances that persist under effective treatments of virological suppression. Although there is evidence that HAART regimes may not be as effective in suppressing viral replication in the brain, improved neurological symptoms and reduced incidences of HAD in HAART-treated patients indicates that there is considerable variability in virological suppression and the progression of neurobehavioral disturbances ${ }^{[29]}$. The noninfectious HIV-Tg rat model may be useful in obtaining information about the vulnerability toward progression of neurological disease despite virological suppression.

\section{ACKNOWLEDGEMENTS}

This work was supported, in part, by R01 DA 007058 (SLC), K02 DA 016149 (SLC) and R21 DA019836 (SLC). The authors would like to thank Ms. Abigail. L. LaShomb for wheel running measurement, Mr. Jose A. Beltran for real time RT-PCR and Dr. Yanhua Ren for cumulative morphine dose-response experiment. 


\section{REFERENCES}

1. Centers for Disease Control and Prevention, 1999. HIV/AIDS Surveillance Report. 11(No.1). Atlanta, GA.

2. Nadeau, L., M. Truchon and C. Biron, 2000. Highrisk sexual behaviors in a context of substance abuse: A focus group approach. J. Subst. Abuse Treat., 19: 319-328.

3. Stall, R., J.P. Paul, G. Greenwood, L.M. Pollack, E. Bein, G.M. Crosby, T.C. Mills, D. Binson, T.J. Coates, J.A. Catania, 2001. Alcohol use, drug use and alcohol-related problems among men who have sex with men: the Urban Men's Health Study. Addiction, 96: 1589-1601.

4. Huba G.J., L.A. Melchior, B. Greenberg, L. Trevithick, R. Feudo, S. Tierney, M. Sturdevant, A. Hodgins, G. Remafedi, E.R. Woods, M. Wallace, A. Schneir, A.K. Kawata, R.E. Brady, B. Singer, K. Marconi, E. Wright and A.T Panter, 2000. Predicting substance abuse among youth with, or at high risk for, HIV. Psychol. Addict. Behav., 14: 197-205.

5. Shah, N.G., N. Galai, D.D. Celentano, D. Vlahov and S.A. Strathdee, 2006. Longitudinal predictors of injection cessation and subsequent relapse among a cohort of injection drug users in Baltimore, MD, 1988-2000. Drug Alcohol Depend., 83: 147-156.

6. Niaura, R., W. Shadel, K. Morrow, T. Flanigan, D. Abrams, 1999. Smoking among HIV-positive persons. Ann. Behav. Med., 21(Suppl.): S116.

7. Stall, R.D., G.L. Greenwood, M. Acree, J. Paul and T.J. Coates, 1999. Cigarette smoking among gay and bisexual men. Am. J. Public Health, 89: 1875-1878.

8. Burkhalter, J.E., C.M. Springer, R. Chhabra, J.S. Ostroff and B.D. Rapkin, 2005. Tobacco use and readiness to quit smoking in low-income HIVinfected persons. Nicotine Tobacco Res., 7: 511-522.

9 Burns, D., D. Hillman, J. Neaton, R. Sherer, T. Mitchell, L. Capps, W.G. Vallier, M.D. Thurnherr and F.M. Gordin, 1996. Cigarette smoking, bacterial pneumonia and other clinical outcomes in HIV-1 infection. J. Acquir. Immune. Defic. Syndr. Hum. Retrovirol., 13: 374-383.

10. Agbottah, E., N. Zhang, S. Dadgar, A. Pumfery, J.D. Wade, C. Zeng and F. Kashanchi, 2006. Inhibition of HIV-1 virus replication using small soluble Tat peptides. Virology, 345: 373-389.

11. Barbaro, G., A. Scozzafava, A. Mastrolorenzo and C.T. Supuran, 2005. Highly active antiretroviral therapy: current state of the art, new agents and their pharmacological interactions useful for improving therapeutic outcome. Curr. Pharm. Des., 11: $1805-1843$.
12. Gianotti, N., A. Lazzarin, 2005. Sequencing antiretroviral drugs for long-lasting suppression of HIV replication. New Microbiol., 28: 281-297.

13. Sleasman, J.W. and M.M. Goodenow, 2003. HIV-1 infection. J. Allergy Clin. Immunol., 111: 582-592.

14. Vigano, A., D. Trabattoni, L. Schneider, F. Ottaviani, A. Aliffi, E. Longhi, S. Rusconi, M. Clerici, 2006. Failure to eradicate HIV despite fully successful HAART initiated in the first days of life. J. Pediatr., 148: 389-391.

15. Kevil, C.G., D.K. Payne, E. Mire and J.S. Alexander, 1998. Vascular permeability factor/vascular endothelial cell growth factormediated permeability occurs through disorganization of endothelial junctional proteins. J. Biol. Chem., 273: 15099-15103.

16. Lucas, S., 2001. Update on the pathology of AIDS. Intens. Crit. Care Nurs., 17: 155-166.

17. Lucas, G.M., L.W. Cheever, R.E. Chaisson and R.D. Moore, 2001. Detrimental effects of continued illicit drug use on the treatment of HIV-1 infection. J. Acquir. Immune Defic. Syndr., 27: 251-259.

18. Lucas, G.M., K.A. Gebo, R.E. Chaisson and R.D. Moore, 2002. Longitudinal assessment of the effects of drug and alcohol abuse on HIV-1 treatment outcomes in an urban clinic. AIDS, 16: 767-774.

19. Donahoe R.M. and D. Vlahov, 1998. Opiates as potential cofactors in progression of HIV-1 infections to AIDS. J. Neuroimmunol., 83: 77-87.

20. McCarthy, L., M. Wetzel, J.K. Sliker, T.K. Eisenstein and T.J. Rogers, 2001. Opioids, opioid receptors and the immune response. Drug Alcohol Depend., 62: 111-123.

21. Weber R.J. and A. Pert, 1989. The periaqueductal gray matter mediates opiate induced immunosuppression. Science, 245: 188-190.

22. Beltran J.A., A. Pallur, S.L. Chang, 2006. HIV-1 gp120 up-regulation of the mu opioid receptor in TPA-differentiated HL-60 cells. Int. Immunopharmacol., in press.

23. Albright A.V., S.S. Soldan and F. GonzalezScarano, 2003. Pathogenesis of human immunodeficiency virus-induced neurological disease. J. Neurovirol., 9: 222-227.

24. Navia B.A. and K. Rostasy, 2005. The AIDS dementia complex: clinical and basic neuroscience with implications for novel molecular therapies. Neurotox. Res., 8: 3-24. 
25. Kaul, M., G.A Garden and S.A. Lipton, 2001. Pathways to neuronal injury and apoptosis in HIVassociated dementia. Nature, 410: 988-994.

26. King, J.E., E.A. Eugenin, C.M. Buckner and J.W. Berman, 2006. HIV tat and neurotoxicity. Microb. Infect., 8: 1347-1357.

27. Koutsilieri, E., S. Sopper, C. Scheller, V. Ter Meulen and P. Riederer, 2002. Parkinsonism in HIV dementia. J. Neural Transm., 109: 767-775.

28. Sacktor, N., M.P. McDermott, K. Marder, G. Schifitto, O.A. Selnes, J.C. McArthur, Y. Stern, S. Albert, D. Palumbo, K. Kieburtz, J.A. De Marcaida, B. Cohen and L. Epstein, 2002. HIVassociated cognitive impairment before and after the advent of combination therapy. J. Neurovirol., 8: 136-142.

29. McArthur, J.C., N. Haughey, S. Gartner, K. Conant, C. Pardo, A. Nath and N. Sacktor, 2003. Human immunodeficiency virus-associated dementia: An evolving disease. J. Neurovirol., 9: 205-221.

30. Berger, J.R., G. Arendt, 2000. HIV dementia: The role of the basal ganglia and dopaminergic systems. J. Psychopharm., 14: 214-221.

31. Ambrose, L.M., E.M. Unterwald and E.J. Van Bockstaele, 2004. Ultrastructural evidence for colocalization of dopamine D2 and mu-opioid receptors in the rat dorsolateral striatum. Anat. Rec. A. Discov. Mol. Cell. Evol. Biol., 279: 583591.

32. Koob, G.F., 2005. The neurocircuitry of addiction: Implications for treatment. Clin. Neurosc. Res., 5: 89-101.

33. Robinson, T.E. and K.C. Berridge, 1993. The neural basis of drug craving: An incentivesensitization theory of addiction. Brain Res. Rev., 18: 247-291.

35. Goeders, E., 2003. The impact of stress on addiction. European Neuropsychopharmacology, 13: 435-441.

34. Vecchiola, A., P. Collyer, R. Figueroa, R. Labarca, G. Bustos and K. Magendzo, 1999. Differential regulation of mu.-opioid receptor mRNA in the nucleus accumbens shell and core accompanying amphetamine behavioral sensitization. Mol. Brain Res., 69: 1-9.

36. Marinelli M. and P.V. Piazza, 2002. Interaction between glucocorticoid hormones, stress and psychostimulant drugs. Eur. J. Neurosci., 16: 387394.
37. Lovallo, W.R., 2006. The hypothalamic-pituitaryadrenocortical axis in addiction. Int. J. Psychophysiol., 59: 193-194.

38. Gosnell, B.A., 2000. Sucrose intake predicts rate of acquisition of cocaine self- administration. Psychopharmacology, 149: 286-292.

39. Piazza P.V., J.M. Deminiere, S. Maccari, P. Mormede, M. Le Moal and H. Simon, 1990. Individual reactivity to novelty predicts probability of amphetamine self-administration. Behav. Pharmacol., 1: 339-345.

40. Larson, E.B. and M.E. Carroll, 2005. Wheel running as a predictor of cocaine selfadministration and reinstatement in female rats. Pharmacol. Biochem. Behav., 82: 590-600.

41. Epling, W.F., W.D. Pierce, 1988. Activity-based anorexia: A biobehavioral perspective. Int. J. Eat. Disord., 7: 475-485.

42. Potvin, S., E. Stip and J.Y. Roy, 2003. Schizophrenia and addiction: An evaluation of the self-medication hypothesis [Schizophrénie et toxicomanie: Une relecture du concept d'automédication]. Encephale, 29: 193-203.

43. Nestler, E.J. and J. Carlezon, 2001. The Mesolimbic Dopamine Reward Circuit in Depression. Biological Psychiatry, Nat. Rev. Neurosci., 2: 119-28.

44. Cicala, C., J. Arthos, S.M. Selig, G. Dennis Jr., D.A. Hosack, D. Van Ryk, M.L. Spangler, T.D. Steenbeke, P. Khazanie, N. Gupta, J. Yang, M. Daucher, R.A. Lempicki and A.S. Fauci, 2002. HIV envelope induces a cascade of cell signals in non-proliferating target cells that favor virus replication. Proc. Natl. Acad. Sci. USA., 99: 93809385.

45. Clapham, P.R., A. McKnight, 2001. HIV-1 receptors and cell tropism. Br. Med. Bull., 58: 4359.

46. Jiang, J., C. Aiken, 2006. Maturation of the viral core enhances the fusion of HIV-1 particles with primary human $\mathrm{T}$ cells and monocyte-derived macrophages. Virology, 346: 460-468.

47. Torensma, R. and C.G. Figdor, 2002. The Achilles' heel of HIV. Medical Hypotheses, 58: 386-387.

48. Trkola, A., 2004. HIV-host interactions: vital to the virus and key to its inhibition. Curr. Opin. Microbiol., 7: 407-411.

49. Verani, A., G. Gras, G. Pancino, 2005. Macrophages and HIV-1: dangerous liaisons. Mol. Immunol., 42: 195-212.

50. Jones, L.E. and A.S. Perelson, 2005. Opportunistic infection as a cause of transient viremia in chronically infected HIV patients under treatment with HAART. Bull. Math. Biol., 67: 1227-1251. 
51. Reid, W., M. Sadowska, F. Denaro, S. Rao, J. Foulke Jr., N. Hayes, O. Jones, D. Doodnauth, H. Davis, A. Sill, P. O'Driscoll, D. Huso, T. Fouts, G. Lewis, M. Hill, R. Kamin-Lewis, C. Wei, P. Ray, R.C. Gallo, M. Reitz and J. Bryant, 2001. An HIV1 transgenic rat that develops HIV-related pathology and immunologic dysfunction. Proc. Natl. Acad. Sci. U.S.A., 98: 9271-9276.

52. Mansour, A, C.A. Fox, H. Akil, S.J. Watson, 1995. Opioid-receptor mRNA expression in the rat CNS: anatomical and functional implications. Trends Neurosci.18:22-29.

53. Paronis, C.A. and S.G. Holtzman, 1991. Increased analgesic potency of $\mathrm{Mu}$ agonists after continuous naloxone infusion in rats. J. Pharmacol. Exp. Ther., 259: 582-589.

54. Beltran J.A., J. Peek, S.L. Chang, 2006. Expression and regulation of the mu opioid peptide receptor in TPA-differentiated HL-60 promyelocytic leukemia cells. Int. Immunopharmacol., in press.

55. Chen Y., A. Meswtek, J. Liu, J.A. Hurley, L. Yu, L., 1993. Molecular cloning and functional expression of a mu-opioid receptor from rat brain. Mol. Pharmacol., 44: 8-12.

56. Proudnikov D, V. Yuferov, Y. Zhou, K.S. LaForge, A. Ho, M.J. Kreek, 2003. Optimizing primer-probe design for fluorescent PCR. J. Neurosci. Methods, 123: 31-45.
57. Diaz, A, A. Pazos, J. Rez, F.J. Ayesta, V. Santana and M.A. Hurle, 2002. Regulation of Mu-opioid receptors, G-protein-coupled receptor kinases and Beta-arrestin 2 in the rat brain after chronic opioid receptor antagonism. Neuroscience, 112: 345-353.

58. Lesscher, H.M.B., A. Bailey, J.P.H. Burbach, J.M. Van Ree, I. Kitchen and M.A.F.M. Gerrits, 2003. Receptor-selective changes in $\mathrm{Mu}-$, Delta- and Kappa-opioid receptors after chronic naltrexone treatment in mice. Eur. J. Neurosci., 17: 10061012.

59. Kenakin, T., 1993. Pharmacologic Analysis Of Drug-Receptor Interaction. 2nd Edn. New York: Raven Press.

60. Matthes, H.W., R. Maldonado, F. Simonin, O. Valverde, S. Slowe and I. Kitchen, et al., 1996. Loss of morphine-induced analgesia, reward effect and withdrawal symptoms in mice lacking the muopioid-receptor gene. Nature, 383: 819-823.

61. Koob, G.F., M. Le Moal, 1997. Drug abuse: Hedonic homeostatic dysregulation. Science, 278: 52-58. 